\title{
Sulcal hyperintensity mimicking subarachnoid hemorrhage in the context of hemiplegic migraine
}

Hiperintensidade de sinal nos sulcos mimetizando hemorragia subaracnoide no contexto de migrânea hemiplégica

Elton Francisco Pavan Batista', Marcos Rosa Júnior', Marcelo Ramos Muniz

A 31-year-old woman with migraine had reversible rightsided hemiplegia followed by a throbbing headache on the left side, and underwent a series of MRI scans over an 18-day period.

Hemiplegic migraine is a rare subtype of migraine with aura, presenting with a completely reversible unilateral weakness associated with migraine. This disorder usually has a familial autosomal dominant inheritance trait but, like our patient, can be sporadic. An MRI can show cortical edema, with sulcal hyperintensity on FLAIR (Figure), this being rare and of uncertain etiology, possibly due to increased vascular permeability during the aura phase mimicking subarachnoid hemorrhage ${ }^{1,2,3}$.
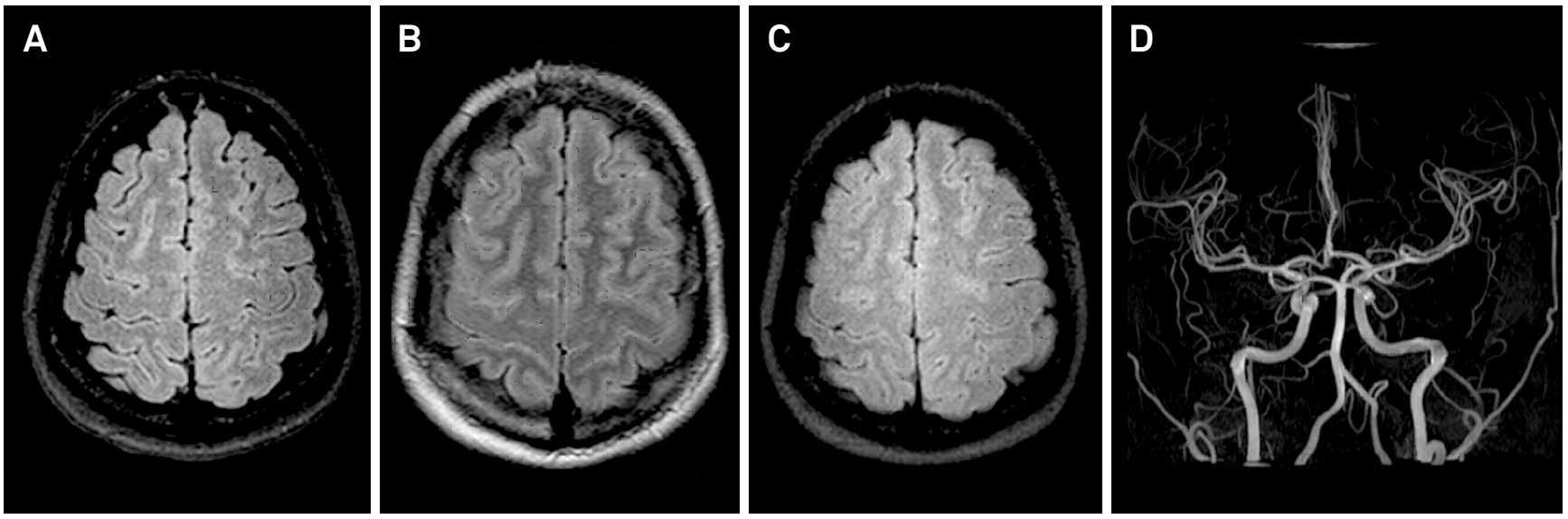

Figure. A) First MRI showed no abnormalities; B) Another MRI, one day later, revealed bilateral sulcal hyperintensity in FLAIR in the brain convexities, reversible in the following control MRI; C) two weeks later; D) MR angiography was also normal.

1. Russell MB, Ducros A. Sporadic and familial hemiplegic migraine: pathophysiological mechanisms, clinical characteristics, diagnosis, and management. Lancet Neurol. 2011;10(5):457-70. https://doi.org/10.1016/S1474-4422(11)70048-5

2. Gómez-Choco M, Capurro S, Obach V. Migraine with aura associated with reversible sulcal hyperintensity in FLAIR. Neurology. 2008;70(24 pt 2):2416-8.

https://doi.org/10.1212/01.wnl.0000314693.57386.fo
3. Bosemani T, Burton VJ, Felling RJ, Leigh R, Oakley C, Poretti A et al. Pediatric hemiplegic migraine: role of multiple MRI techniques in evaluation of reversible hypoperfusion. Cephalalgia. 2014;34(4):311-5. https://doi.org/10.1177/0333102413509432

4. Figure. A) First MRI showed no abnormalities; B) Another MRI, one day later, revealed bilateral sulcal hyperintensity in FLAIR in the brain convexities, reversible in the following control MRI; C) two weeks later; D) MR angiography was also normal.

${ }^{1}$ Universidade Federal do Espírito Santo, Departamento de Radiolodia, Vitória ES, Brasil.

Correspondence: Marcos Rosa Júnior; Centro de Ciências da Saúde da UFES; Av Marechal Campos, 1468; 29040-090 Vitória ES, Brasil.

E-mail:marcosrosajr@hotmail.com

Conflict of interest: There is no conflict of interest to declare.

Received 24 December 2016; Received in final form 11 August 2017; Accepted 28 August 2017. 